\title{
LOS LAPIACES DE AGUJAS DE PEÑA CABARGA (CANTABRIA). GENESIS Y SIGNIFICADO DE UNA FORMA ORIGINAL
}

\author{
Juan Carlos García Codrón*
}

\begin{abstract}
RESUMEN
Las actividades mineras a cielo abierto han permitido la exhumación en varios puntos del norte de España de vistosos karsts de agujas y pitones. Consideradas sin fundamento como herencia de una época con «clima tropical», estas formas deben atribuirse a la alteración de los sulfuros metálicos y a la conjunción actual de diversos factores favorables a la karstificación.
\end{abstract}

\section{SUMMARY}

Gaudy cone and pinnacle karsts have been exhumed in many points of Northern Spain by open pit mining activities. Usually considered, without a real basis, as a "tropical climate» inheritance, these forms must be explained as result of iron and lead sulphides alteration in an environment with a conjunction of favourable conditions to karst processes in present-day.

\section{RÉSUMÉ}

De frappants karsts à aiguilles et à chicots ont été exhumés à plusieurs endroits du nord de l'Espagne par les activités minières à ciel ouvert. Considérées a tort jusqu'a présent en tant qu'héritage morphoclimatique d'une époque a «climat tropical», ces formes doivent-être interprétées comme le résultat de l'altération des sulfures métalliques et de la conjonction actuelle de diverses circonstances favorables au développement $d u$ karst.

PALABRAS CLAVE: Karst, Cantabria, lapiaz.

KEY WORDS: Karst, Cantabria, lapiaz.

* Dpto. Geografia, Urbanismo y Ordenación del Territorio, Universidad de Cantabria. 


\section{GARCIA CODRON}

En varios puntos de Cantabria y de Vizcaya se han desarrollado de forma continua desde época antigua diversas actividades mineras a cielo abierto gracias a la frecuencia de depósitos arcillosos, ricos en hierro, plomo y cinc. En algunos casos, tales depósitos se limitan a rellenar fracturas y presentan por ello un desarrollo reducido. En otros sin embargo las arcillas, que aparecen en superficie, recubren ininterrumpidamente extensiones de cierta importancia adquiriendo entonces las explotaciones una considerable magnitud.

La extracción de las arcillas, que en todos los casos reposan sobre calizas muy dolomitizadas, ha supuesto la progresiva exhumación de una espectacular topografia kárstica de pitones y agujas que, dada la extensión de algunas de las explotaciones, puede parangonarse en interés y valor paisajístico con las mejores «ciudades encantadas» de Europa a pesar de haber permanecido prácticamente desconocida hasta la actualidad (hablándose paradójicamente en estos momentos de crear un zoológico y diversas atracciones turísticas que podrían desfigurar irreversiblemente el mejor de estos enclaves).

El karst de Peña Cabarga, en el que se va a centrar el presente trabajo, ocupa toda la vertiente meridional de dicha eminencia, al sur de la Bahía de Santander, entre los 500 y los 100 metros de altitud ocupando la topografia ya exhumada una superficie aproximada de 270 has. (aunque la concesión de AGRUMINSA, la empresa de la que depende la explotación actual, alcanza las 949 has. lo que hace verosímil un aumento futuro de la superficie visitable).

El interés de las formas subterráneas es muy limitado en el karst de Peña Cabarga: así, aunque existen al menos una docena de cavidades significativas, la mayoría se encuentran en la periferia de la sierra, separadas de los lapiaces, sin relación genética aparente con las formas superficiales y sin alcanzar en ningún caso el desarrollo que cabría imaginar en un macizo con el volumen del que nos ocupa. Sólo es digna por ello de mención la sima que se utiliza como sumidero de las aguas de la mina, situada en una depresión en medio del lapiaz, aunque resulta dificil imaginar su funcionalidad previa a la alteración de la topografia por la explotación minera.

Frente a ello, las formas superficiales (o desarrolladas bajo cubierta edáfica) presentan un extraordinario desarrollo y originalidad: mientras que las formas de conducción verdaderas son inexistentes y las dolinas no aparecen más que en los rellanos culminantes de la sierra, dispuestas de acuerdo con la fracturación y los contactos litológicos, el resto del karst está ocupado por un laberíntico lapiaz constituido por agujas cónicas a piramidales de alturas variables entre los 5 y los 15 metros separadas por callejones que, en ocasiones, no superan en la base más de un par de metros de anchura.

Aunque el reconocimiento exhaustivo sobre el terreno es dificil por aparecer el karst parcialmente relleno de arcillas o escombros y por estar localmente colonizado por una exhuberante vegetación, un examen de la fotografia aérea demuestra claramente la relación existente entre los callejones de lapiaz y la compleja red de fracturas del macizo. Así, al W del mismo, entre Obregón y Liaño, predoniman las diaclasas y microfallas con orientaciones NNW-SSE y NNE-SSW (lo que determina una red rómbica muy clara) mientras que al S, cerca de Cabárceno, el campo regmático dibuja una red de triángulos para adquirir un trazado prácticamente ortogonal, con direcciones predominantes $\mathrm{N}-\mathrm{S}$ y E-W, en la proximidades de Elsedo relacionándose estos cambios de dirección con la disposición de las grandes líneas estructurales que enmarcan y fragmentan el macizo de Peña Cabarga. Estas fracturas, responsables de la orientación y profundidad de los callejones de lapiaz, se entrecruzan formando mallas más o menos densas de las que depende el desarrollo de las agujas, resaltes residuales cuyas culminaciones permiten reconstruir sin dificultad la topografía previa a la exhumación del karst por el hombre.

En algunos lugares, allí donde se entrecruzan haces complejos de diaclasas, o donde éstas confluyen con algunas de las fallas que surcan el macizo, las dolomías de que está compuesto 


\section{LOS LAPIACES DE PEÑA CABARGA}

han sufrido una disolución más importante apareciendo auténticas torcas de diámetro hectométrico y varias decenas de metros de profundidad relativa (torcas que, al aparecer rellenas de arcillas mineralizadas, constituyen bolsones de mineral especialmente perseguidos $\mathrm{y}$, por la misma razón, desfigurados por la explotación ya que en estos lugares se utilizan técnicas duras» que incluyen la voladura y evacuación de los pitones calizos que molestan o ponen en peligro el paso de vehículos y maquinaria pesada).

La originalidad de este modelado en el contexto europeo, su similitud con los descritos por varios autores en Madagascar, Sarawak u otros puntos (al menos en apariencia tras el análisis somero que permiten los documentos disponibles) y el mismo relleno a base de arcillas rojas con depósitos de hierro, supuestamente comparables a las costras lateríticas, ha hecho que estos karsts se describan siempre como «tropicales» a pesar de no haber sido nunca estudiados con un mínimo detenimiento.

En esta línea, las escasas citas que existen del karst de Peña Cabarga (o de los otros que en la región comparten sus caracteres esenciales) los describen como herencias de un período cálido y húmedo situado en un mal precisado momento del Pleistoceno. Así, en el «Proyecto de explotación y tratamiento de tierras mineralizadas...» elaborado para AGRUMINSA, los autores se contentan con reproducir literalmente una frase absolutamente discutible que Llopis Lladó acuñó hace ya tiempo al describir el karst de Llanes según la cual (LLOPIS, 1970) nos encontraríamos ante un «karst tropical, desarrollado durante el interglaciar Mindel-Riss, interglaciar de clima excesivamente templado, es decir, llegando a cálido, llegando a tropical solamente en esta región de España» para afirmar a continuación que ello se debería a que «en esta zona en la vertiente septentrional de los Picos de Europa aparece un microclima definido y concreto, distinto a todos los microclimas locales que pueden aparecer en la región cantábrica» (GOMEZ, PEDRAJO, GONZALEZ, 1980), frase que, independientemente de haber sido redactada para una región distinta de la que nos ocupa, resulta insostenible a la luz de los conocimientos actuales sobre el Cuaternario y sobre el mosaico de los microclimas cantábricos actuales y pasados.

Según esta interpretación, durante el Pleistoceno se produciría por tanto la génesis de un lapiaz «de tipo tropical» que, inmediatamente sufrió un relleno con arcillas metalíferas de origen mal conocido para, una vez fosilizado por completo el karst, seguir evolucionando el macizo de forma convencional hasta dar el relieve actual: sobre la superficie karstificada y enrasada por las arcillas se observa, en efecto, una red hidrográfica incipiente y diversos procesos de vertiente favorecidos por el vigor del relieve y por la plasticidad o escasa coherencia de los depósitos superficiales.

La inexistencia de depósitos cuaternarios significativos diferentes a las arcillas de decalcificación, la falta de relación aparente con los sedimentos estudiados en las cavidades de la zona (de entre las que destaca Cueva Morín que ha proporcionado una secuencia arqueológica de calidad) y la alteración del medio por las actividades extractivas dificulta la obtención de evidencias a favor o en contra de la interpretación más comúnmente admitida. Creemos sin embargo que ésta adolece de excesivos puntos oscuros y de ciertas incoherencias.

Aparte de los lapiaces objeto de este trabajo no existe en la región ningún depósito ni forma que pueda relacionarse inequivocamente con un «ambiente tropical» cuaternario (las discutibles «terras rossas» que rellenan algunas grandes depresiones calizas y que habitualmente se consideran como relícticas aparecen siempre asociadas a mineralizaciones de hierro como las que nos ocupan y presentan una problemática similar pudiendo, por otra parte, corresponder a un ambiente de «tipo mediterráneo»). Parece sorprendente que caso de haberse producido estas circunstancias durante el tiempo necesario para la karstificación del macizo, todas las demás huellas hayan podido desaparecer. 


\section{GARCIA CODRON}

Por otra parte, los lapiaces que nos ocupan presentan un desarrollo independiente de la posición topográfica: existen agujas en piedemontes o en el fondo de depresiones considerables, en zonas muy húmedas o incluso más o menos palustres en las que la disolución ha podido ser muy muy rápida (Ruiloba, Novales, Solares, Camargo), pero las agujas abundan también en collados o en zonas culminantes (Peña Cabarga, El Bosque, La Arboleda, Hornijo) en los que la cantidad de agua disponible es inferior dada la rapidez de la escorrentía. Esta similitud entre los lapiaces culminantes y los que ocupan las depresiones no parece corresponderse con las topografias kársticas tropicales descritas por diversos autores (WILLIAMS, 1987).

Por fin, si admitimos la hipótesis del «karst tropical», hay que explicar la procedencia del relleno, problema éste que se vuelve insoluble si tenemos en cuenta la citada posición culminante de los lapiaces (tratándose de formas pleistocenas no cabe invocar diferencias apreciables en la distribución de las formas de relieve). No resulta por otra parte fácil imaginar cómo se ha realizado el transporte de un volumen tan grande de arcillas supuestamente alóctonas a través del lapiaz para repartirse uniformemente desde su base hasta su culminación salvando obstáculos de escala decamétrica, desniveles de varios cientos de metros y distancias lineales del orden, como mínimo, del kilómetro. Y aun admitiendo que ello fuera posible, quedaría sin resolver el problema del origen estratigráfico del mineral: el hierro no aparece en proporciones significativas fuera de los niveles aptienses o, localmente, cenomanenses. La existencia de lapiaces de agujas lejos de todo diapiro (Novales, Alto de San Mateo, yacimientos vizcainos...) descarta, por fin, la posibilidad de que las mineralizaciones puedan tener relación con las extrusiones tal como se ha insinuado en algunas ocasiones. Creemos por ello que el relleno es consecuencia de la evolución in situ de los materiales aptienses (a los que aparece siempre asociado) y que, aunque puedan haberse dado procesos locales de transporte, nada permite suponer que éste se haya producido a gran escala.

\section{EL RELLENO DEL KARST}

Los depósitos que rellenan el karst de Peña Cabarga, similares a los que aparecen en el resto de la región, consisten en arcillas rojas que encierran diversos sulfuros y óxidos de hierro en forma de nódulos o de geles. Las dimensiones de éstos, muy desiguales, están comprendidas entre unos milímetros y varios decímetros sumando una proporción variable pero próxima al $30 \%$ del peso total del depósito. Estas metalizaciones de sulfuros aparecen siempre asociadas a las dolomías aptienses, normalmente en los niveles Gargasiense y Clansayense, observándose una mayor riqueza en hierro a medida que se avanza hacia el $\mathrm{E}$ (la ley de recuperación de las explotaciones es máxima en los yacimientos vizcainos) mientras que en dirección opuesta dicho metal es progresivamente sustituido por el cinc y el plomo (predominantes ya en las minas de Reocín, Novales y Udías). En cualquier caso, los yacimientos metalíferos coinciden siempre con estratos de calizas arrecifales (en Mercadal se ha llegado a observar incluso cómo las zonas estériles coinciden con los canales interarrecifales) determinando a su vez la presencia de los organismos constructores la dolomitización de los depósitos.

Los minerales metálicos más abundantes en el relleno de los lapiaces son los siguientes:

Melnikovita, gel de bisulfuro de hierro que se forma en marismas o precipita en fuentes termales y que se altera con gran rapidez dando marcasita por recristalización.

Marcasita $\left(\mathrm{S}_{2} \mathrm{Fe}\right)$ que se forma cerca de la superficie, a baja temperatura y a expensas de disoluciones ácidas o aparece en forma de concreciones en rocas sedimentarias inicialmente fangosas. En condiciones normales se descompone a temperatura ambiente y con la simple 


\section{LOS LAPIACES DE PEÑA CABARGA}

humedad atmosférica disociándose el azufre (que da sulfato ferroso y ácido sulfúrico) del hierro (que por oxidación da oligisto y tras hidratación limonita).

Oligistio $\left(\mathrm{Fe}_{2} \mathrm{O}_{3}\right)$, Goethita $\left(\mathrm{Fe}_{2} \mathrm{O}_{3} \mathrm{H}_{2} \mathrm{O}\right)$, Limonita $\left(\mathrm{Fe}_{2} \mathrm{O}_{3} \cdot 1^{1 / 2} \mathrm{H}_{2} \mathrm{O}\right)$, Lepidocrocita y otros, todos ellos productos típicos de la meteorización de minerales ferríferos bajo condiciones oxidantes, a temperaturas ordinarias y a flor de suelo. Son formaciones que se hidratan y deshidratan fácilmente lo que hace predominar uno u otro mineral de forma alternativa (aunque, en la práctica, suelen resultar indisociables tal y como ocurre en Peña Cabarga).

\section{ORIGEN DE LAS METALIZACIONES Y DE SU DISTRIBUCION}

Los lapiaces de agujas se desarrollan siempre sobre los depósitos carbonatados aptienses que constituyen el denominado "Complejo Urgoniano Cantábrico» (RAT, 1959). Bajo él encontramos las potentes series terrígenas wealdenses que por su impermeabilidad y potencia constituyen el nivel de base estructural del karst de la región.

El Complejo Urgoniano presenta en su base $650 \mathrm{~m}$. de calizas, intensamente dolomitizadas en su tramo inferior y con mineralizaciones (como promedio, el contenido en hierro de la formación es del 2,3\%) tramo que, progresivamente, va dando paso a calizas apareciendo entonces calcarenitas microcristalinas (biomicritas). Por encima, nos encontramos de nuevo con niveles dolomíticos con intercalaciones de calizas arcillosas y, por fin, en el techo de la serie, con calizas microcristalinas grises y oscuras, estratificadas en bancos delgados.

Salvo por la presencia de un nivel ferruginoso en el Cenomanense (que podría deberse a una removilización de los depósitos aptienses) los niveles posteriores, que no contienen metales, no parecen guardar ninguna relación con la problemática que nos ocupa y no van a ser descritos aquí (por otra parte, en la mayor parte de los casos, los afloramientos urgonianos sobre los que se ha instalado el karst no están recubiertos por ningún otro material pretectónico).

Todos estos depósitos proceden de una sedimentación en una cuenca de tipo nerítico o epicontinental (profundidades de 30 a $50 \mathrm{~m}$.), en la que debían reunirse condiciones favorables para el desarrollo de organismos constructores. El medio no debía presentar un índice de energía muy alto (presencia de calizas micríticas) y las aguas debían ser relativamente cálidas (frecuencia de las orbitolinas).

Sin embargo, las cuencas en las que se produjo la sedimentación debían ser bastante inestables lo que justifica la brusquedad de los cambios de facies y de espesores y la existencia de numerosos umbrales y surcos de rápida evolución. Sucesivos aportes terrígenos bloquean frecuentemente el desarrollo de los arrecifes lo que, con el tiempo, se traducirá en una muy desigual dolomitización de los materiales.

En este contexto, la acumulación y descomposición anaeróbica de la materia orgánica daría lugar al ambiente reductor necesario para la formación de sulfuros. En cuanto a la precipitación de éstos, se produciría gracias a la actividad bacteriana (igual que a las bacterias ferríferas deberíamos la separación y acumulación del hierro) (CLINTON, 1986).

Tras su deposición, las calizas sufrieron un intenso metasomatismo que dio lugar a una dolomitización muy desigual en intensidad y destribución y, simultáneamente, a la aparición de depósitos de sulfuros de hierro (o de los demás metales que aparecen asociados a él) intercalados entre las dolomías. 


\section{GARCIA CODRON}

Con posterioridad, aunque en época temprana (téngase en cuenta la inestabilidad de esta cuenca durante todo el Mesozoico) algunas de las mineralizaciones sufrieron una movilización que hizo aún más irregular de lo que ya era la presencia de lentejones o rellenos. Una nueva redistribución, aunque en este caso de carácter local, pudo producirse a lo largo de las fases álgidas del Plegamiento Alpino durante las que las mineralizaciones rellenaron, gracias a la presencia de abundantes aguas cloruradas y termales, un cierto número de fracturas en los yacimientos más occidentales y llegaron a formar grandes masas a lo largo de determinados accidentes tectónicos y topográficos. El relativo redondeamiento de los cantos y la disposición en bancos más o menos paralelos que algunos autores citan en el karst de Peña Cabarga (GOMEZ, PEDRAJO, GONZALEZ, 1980), y que, probablemente destruidos por la propia explotación, no hemos tenido ocasión de observar, parecen corroborar la hipótesis de una redistribución local por aguas corrientes.

El plegamiento alpino se inicia en época muy temprana con diversas manifestaciones neokimméricas que producen movimientos intraweáldicos, aptienses y albense-cenomanenses. Tales movimientos, responsables de los ya comentados cambios bruscos de potencias, desempeñaron sin duda un importante papel en la irregular distribución de las acumulaciones de hierro y son responsables de los hiatos sedimentarios post-urgonianos.

Los movimientos más importantes fueron sin embargo los correspondientes a las fases Pirenaica, Sávica y Estírica cuya principal consecuencia fue la fracturación de las series sedimentarias y la inyección diapírica de los materiales plásticos del Keuper a través de toda la cobertura mesozoica y, eventualmente, eocena. Aunque no disponemos de elementos de juicio en la zona objeto de nuestro estudio (donde no existen afloramientos terciarios) toda parece indicar que estos movimientos se prolongaron hasta época avanzada (en el occidente de la región los diapiros atraviesan formaciones priabonienses y oligocenas abundando las manifestaciones neotectónicas en torno a los mismos).

\section{PEÑA CABARGA}

Resultado de esta evolución encontramos el gran bloque de Peña Cabarga que nos muestra una serie seudomonoclinal aptiense-albense, intensamente fracturada dada la rigidez y masividad del Urgoniano y muy inclinada hacia el $\mathrm{N}$. La vertiente septentrional de dicho bloque muestra una brusca inflexión de los buzamientos que, tras un violento pliegue, llegan a aparecer invertidos.

La Peña Cabarga está perfectamente delimitada por fracturas y flanqueada por los diapiros de Solares, Marina de Cudeyo, Parbayón, Obregón y Sarón, culpables de la disposición e intensa fracturación de las calizas del macizo (aunque en sus límites sur y este, los que más nos interesan, el contacto entre las rocas carbonatadas y las de origen diapírico es muy neto y los diapiros no parecen haber afectado demasiado a la disposición local de las calizas).

El karst de Peña Cabarga se ha instalado en el dorso de esta estructura, determinado por el techo de los niveles aptienses. Su antigüedad es difícil de estimar a falta de indicadores utilizables. Es evidente en todo caso que su desarrollo es postectónico: las agujas son perfectamente verticales independientemente del buzamiento, a veces muy fuerte, de los bancos en los que se han formado y los callejones de lapiaz se superponen exactamente, como ya se ha comentado, a la red de fracturas alpinas. Las escasas agujas que aparecen inclinadas se deben probablemente a anomalías locales en la fracturación (o incluso a deslizamientos de pequeñas unidades) pero al estar rodeadas de formas verticales no pueden atribuirse a la tectónica del conjunto plegado. 


\section{LOS LAPIACES DE PENAA CABARGA}

De la misma manera, el karst se inscribe sobre un paleorrelieve inicial, no concordante con la estratificación, bastante evolucionado en apariencia con, incluso, una red de drenaje organizada que, de nuevo, es claramente tributaria de las principales fracturas del macizo.

En aquellas zonas donde el conjunto no ha sido excesivamente desfigurado, predominan, por fin, formas aparentemente funcionales: el lapiaz y las dolinas que se han desarrollado en las zonas culminantes a favor de estratificación y fracturas actúan como formas de absorción; la red de conductos que drena las aguas subterráneas es rara vez penetrable pero las cavidades visitables son funcionales $y$ conducen el agua hacia las numerosas resurgencias que circundan la periferia de Peña Cabarga. Todo parece indicar que nos encontramos ante un karst actual de origen no excesivamente remoto, karst que, en su mayor parte, se desarrolla bajo una espesa cubierta edáfica que engloba las mineralizaciones en forma de nódulos.

\section{GENESIS DEL LAPIAZ}

La interpretación de la originalidad del lapiaz de Peña Cabarga no debe buscarse en un más que dudoso pasado morfoclimático sino en su contexto litológico (y, con él, edáfico). Los lapiaces de agujas aparecen siempre asociados a los sulfuros y a los óxidos de hierro y desaparecen alli donde no existen dichas mineralizaciones.

Muy en síntesis, la cadena de reacciones se iniciaría con la oxidación en superficie (o en los horizontes superiores) de los sulfuros de hierro. Esta origina sulfatos que, por hidrólisis, dan ácido sulfúrico. La reacción del ácido con los carbonatos permite su disolución que se acompaña de la precipitación de nuevos sulfatos, fácilmente eliminados por el agua.

$$
\begin{array}{ll}
\mathrm{FeS}_{2}+8 \mathrm{H}_{2} \mathrm{O} \rightarrow & \mathrm{H}_{2} \mathrm{SO}_{4}+\mathrm{FeSO}_{4}+7 \mathrm{H}_{2} \\
2 \mathrm{FeSO}_{4}+3 \mathrm{H}_{2} \mathrm{O} \rightarrow & 2 \mathrm{H}_{2} \mathrm{SO}_{4}+\mathrm{Fe}_{2} \mathrm{O}_{3}+\mathrm{H}_{2} \\
\mathrm{H}_{2} \mathrm{SO}_{4}+\mathrm{CaCO}_{3} \rightarrow & \mathrm{CaSO}_{4}+\mathrm{CO}_{2}+\mathrm{H}_{2} \mathrm{O}
\end{array}
$$

Esta cadena de reacciones permite además la liberación de gas carbónico que aumentará la presión de $\mathrm{CO}_{2}$ del suelo $\mathrm{y}$, con ella, la agresividad del agua... todo conduce a una rápida disolución de las calizas o dolomías bajo las arcillas, disolución que se produce de forma ininterrumpida en tanto queden sulfuros sin alterar.

Existen otro tipo de argumentos a favor de esta interpretación como puede ser el hecho de que los sulfuros aparezcan siempre oxidados en superficie; la distribución vertical de los sulfuros y de los óxidos e hidróxidos de hierro a través del grueso relleno arcilloso; el elevado contenido en sulfatos de las aguas de percolación o la formación frecuente de una costra caliza en la base del depósito (concreción que se debería a la reacción que se produce entre el agua carbonatada y el sulfato de calcio liberado por el proceso descrito).

Volviendo a los mecanismos que determinan la disolución de las calizas, a esta rápida acidificación del agua por los sulfatos acompañada de la liberación de gas carbónico hay que añadir una serie de factores locales como son la elevada pluviometría (que permite un favorable balance hídrico gracias al cual la franja de contacto entre el suelo y la caliza permanece habitualmente húmeda) y la presencia frecuente de aguas termales y cloruradas que resurgen a favor de las principales fallas. 


\section{GARCIA CODRON}

Este conjunto de circunstancias permite una rápida karstificación de unas calizas que, por otra parte, son de una gran pureza (94-96\% de carbonatos solubles) y presentan siempre una intensa fracturación. Así, las aguas que resurgen en la periferia de Peña Cabarga suelen aparecer sobresaturadas de carbonatos (con contenidos que pueden alcanzar los $240 \mathrm{mg} / \mathrm{l}$ ). Pensamos que todo ello basta para justificar la existencia de los lapiaces y poner en duda su consideración habitual como herencia paleoclimática.

Pero es más, estos argumentos pueden utilizarse de forma inversa: existen lapiaces de agujas en lugares elevados de la región (Sierra del Hornijo-Alto Asón, Macizo del Porracolina) expuestos a la intemperie en lugares que reciben cerca de $2.000 \mathrm{~mm}$. anuales de precipitación. Parece contrario a toda lógica que en tales circunstancias hayan podido conservarse intactos unos lapiaces del «Mindel-Riss» cuando la topografía glaciar wurmiense aparece ya sobre las calizas de dichas sierras completamente desfigurada por la karstificación. No nos encontramos ante un karst tropical sino, como en tantos otros casos europeos (FAVORY, GAZELLE, 1981), ante un caso de convergencia de formas favorecida en uno y otro dominio por la extraordinaria efectividad de la disolución.

AGRADECIMIENTOS: Deseamos agradecer las facilidades ofrecidas por la dirección de AGRUMINSA que a través de Rebeca Montes nos permitió visitar la explotación y puso a nuestra disposición cuanta información solicitamos.

\section{BIBLIOGRAFIA.}

Clinton, J.D., 1986. Botánica marina. Limusa, Mexico.

FAvory, M.; Gazelle, F., 1981. Modelé karstique et comportement hydrologique des calcaires primaires dans le sud du Massif Central. Rev. Geog. Pyr. S.O. 52, 2 pág. 173-200.

Gomez De Cos, M.F.; Pedrajo Perez, M.A.; Gonzalez Cubillos, A.I., 1980. Proyecto para la explotación y tratamiento de tierras mineralizadas en el karst de Peña Cabarga (Santander). AGRUMINSA, informe inédito.

Guendon, J.L.; SAlomon, J.N.; Nicod, J., 1987. Karstification sous couverture, comparaison entre karst tropical actuel et paleokarst. Ann. Géog. 537, pág. 557-563.

HAZERA, J., 1981. Altération des calcaires greseux du «Complexe urgonien» cantabrique. Estudios de Geografía. Homenaje a Alfredo Floristán, Pamplona.

JENNINGS, J.N., 1985. Karst Geomorphology. Basil Blackwell, Oxford.

Llopis Llado, N., 1970. Fundamentos de hidrogeología carstica. Blume, Madrid.

Rat, P., 1959. Les Pays Crétacés Basco-Cantabriques (Espagne). Publ. Univ. Dijon., Dijon.

Williams, P.W., 1987. Development of tower karst. Earth Surface Processes and Landforms. 5, 12, pág. 453-66. 


\section{LOS LAPIACES DE PEÑA CABARGA}
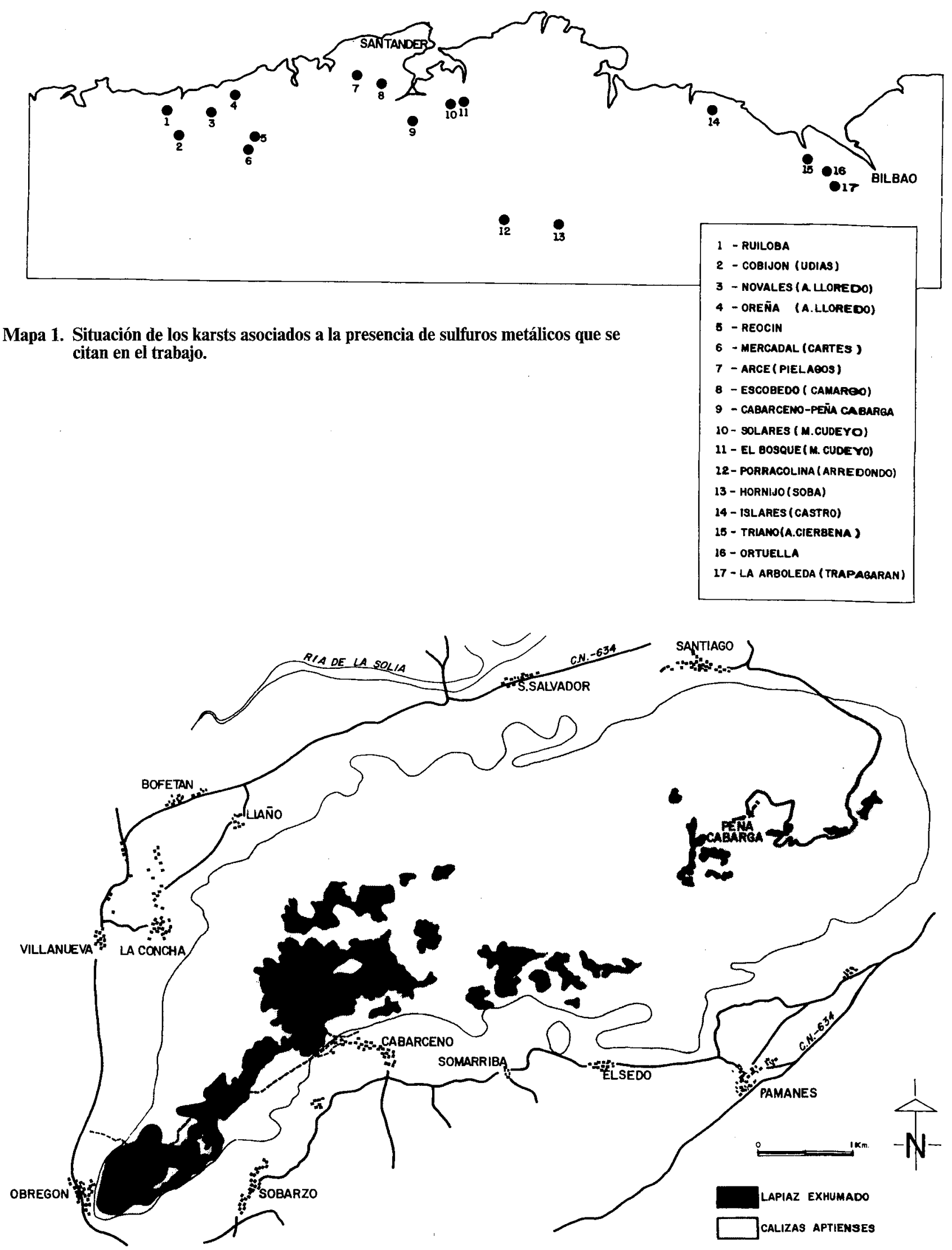

Mapa 2. Macizo de Peña Cabarga: afloramiento de calizas aptienses y áreas en las que el lapiaz ha sido exhumado. Las actividades extractivas actuales se centran en las proximidades de Obregón y al norte de Cabárceno. (A partir de fotografía aérea; escala aproximada). 


\section{GARCIA CODRON}

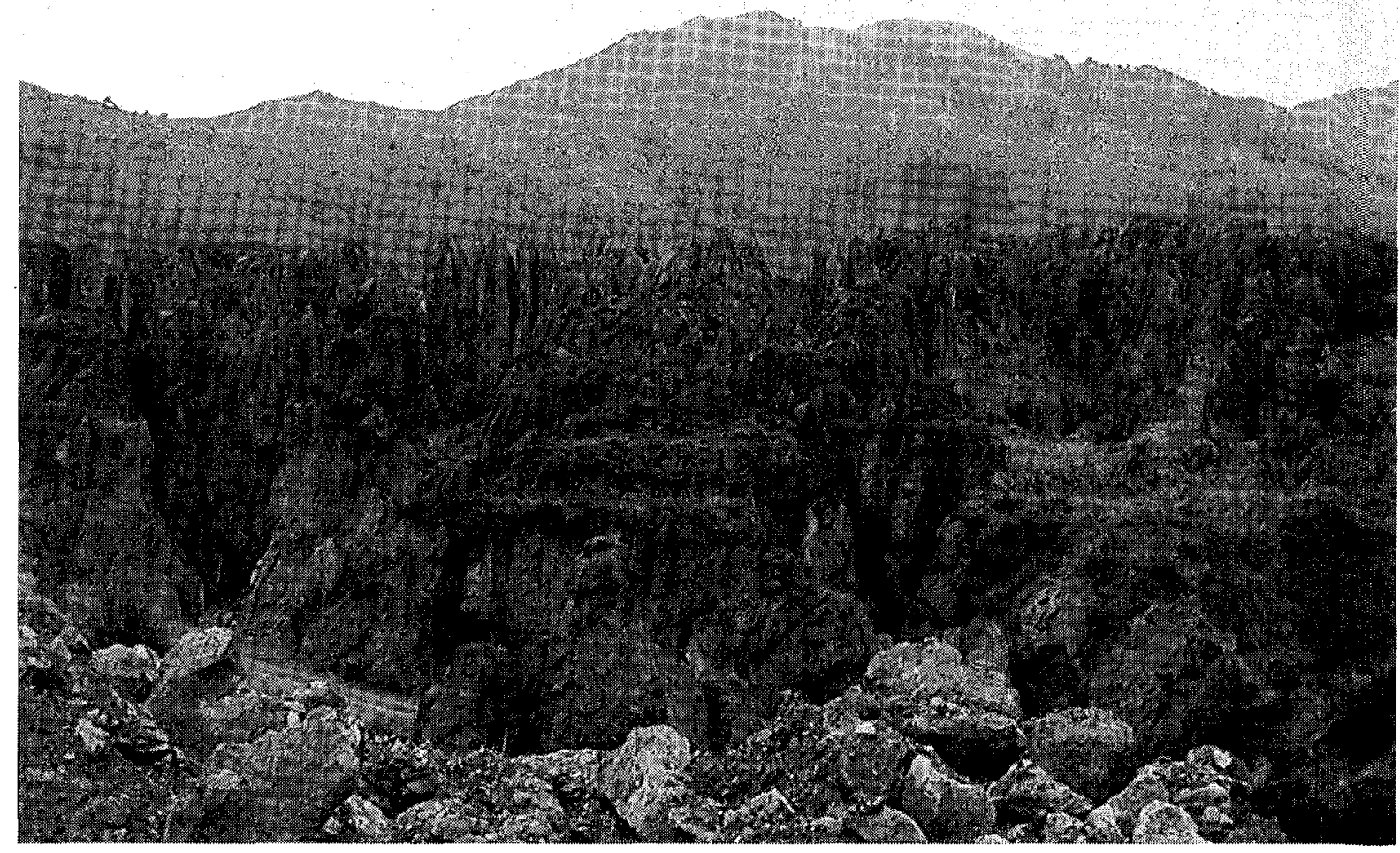

Foto 1. Vertiente meridional del macizo de Peña Cabarga. Tras el depósito caótico de los bloques abandonados por la explotación aparecen los lapiaces. Se observa como las culminaciones de las agujas permiten retrazar con facilidad el relieve preexistente.

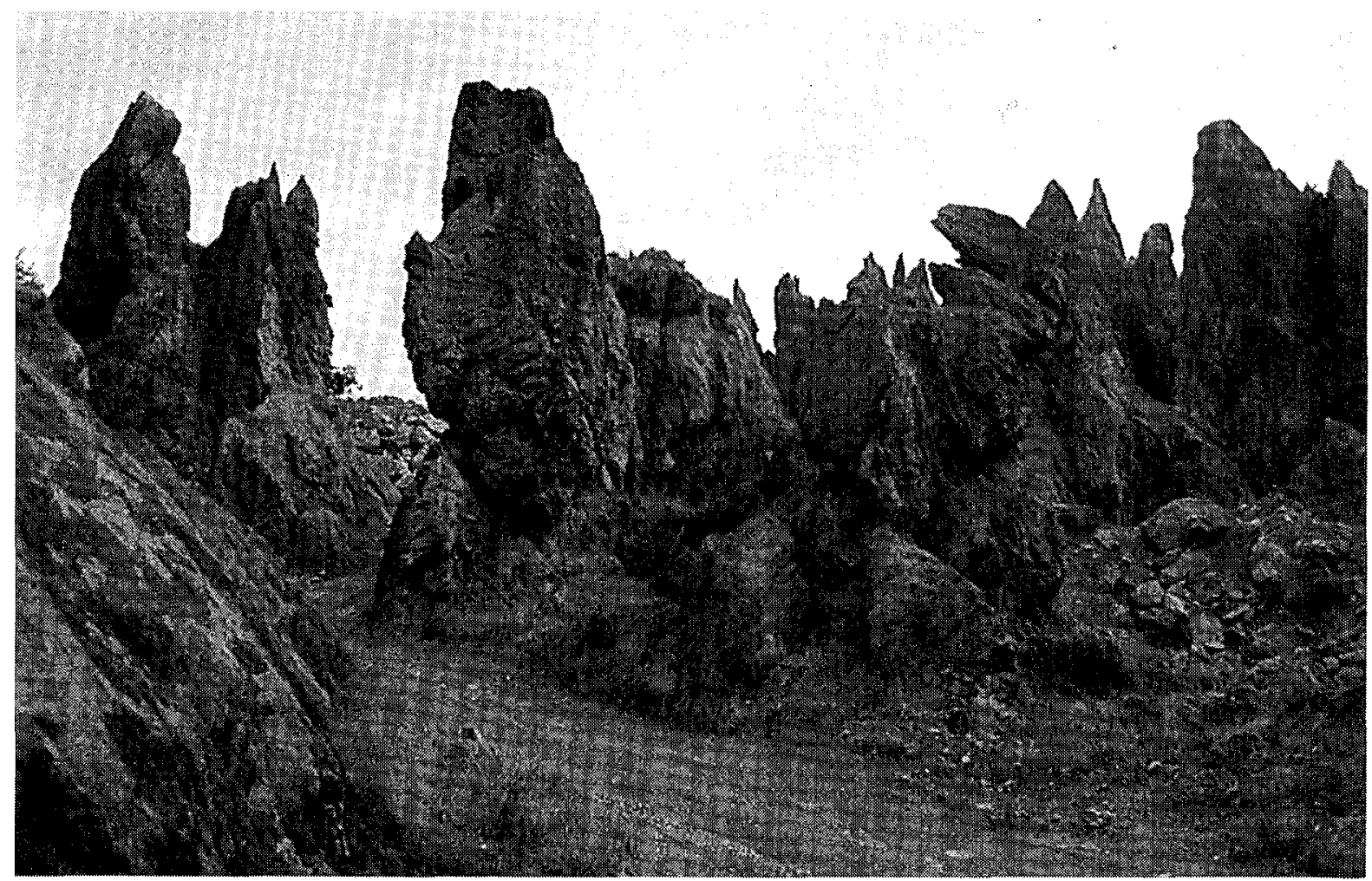

Foto 2. Agujas exhumadas en las proximidades de Cabárceno. 


\section{LOS LAPIACES DE PEÑA CABARGA}

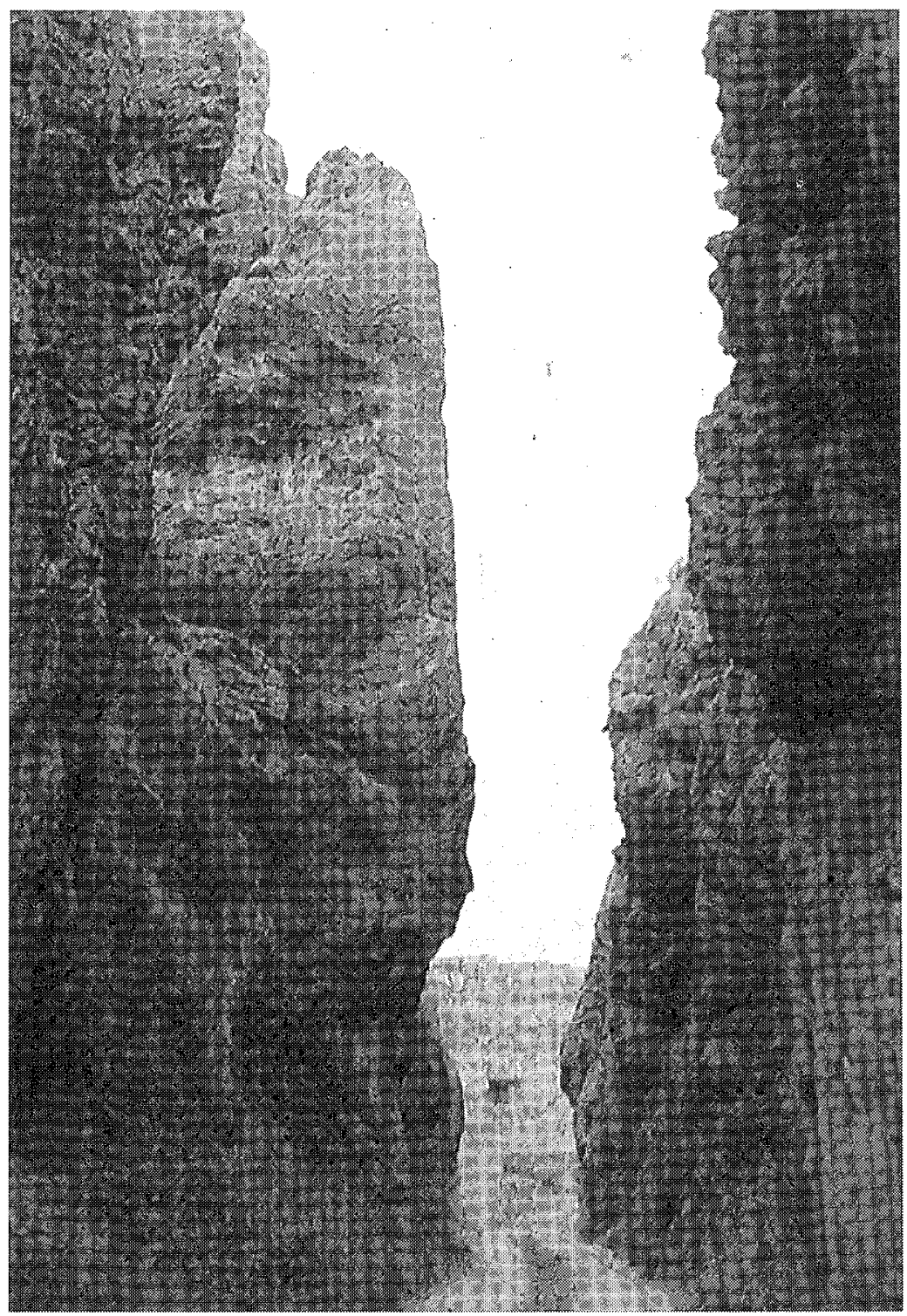

Foto 3. Callejón de lapiaz desarrollado sobre fractura. Con una anchura de 3 metros en su base tiene una profundidad de cerca de 30 . Independientemente de la escorrentía, ha sido exhumado, igual que el resto de las formas superficiales, al extraerse las arcillas que lo rellenaban. 


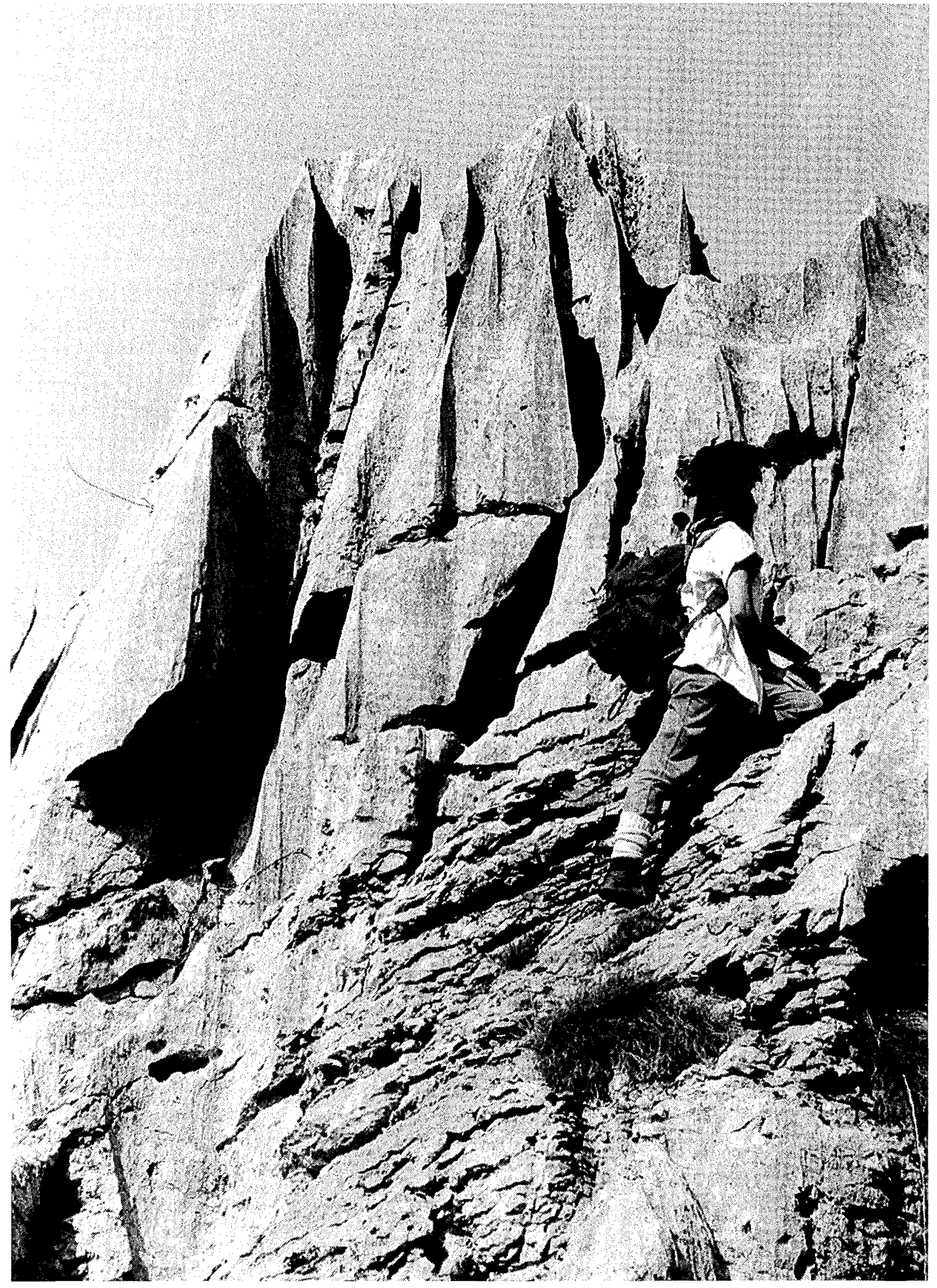

Foto 4. Lapiaces de agujas en el macizo de Porracolina. Desarrollados en calizas aptienses similares a las de Peña Cabarga, muestran una rápida evolución actual independiente de toda cubierta edáfica. (Foto cedida por R. Gandarillas, L. Rebolledo, M. R. Castillo y F. S. Rebanal). 